\title{
Mitochondrial Superoxide Production and Nuclear Factor Erythroid 2-Related Factor 2 Activation in p75 Neurotrophin Receptor-Induced Motor Neuron Apoptosis
}

\author{
Mariana Pehar, ${ }^{1}$ Marcelo R. Vargas, ${ }^{1}$ Kristine M. Robinson, ${ }^{4}$ Patricia Cassina, ${ }^{2}$ Pablo J. Díaz-Amarilla, ${ }^{1}$ Tory M. Hagen, ${ }^{4}$ \\ Rafael Radi, ${ }^{3}$ Luis Barbeito, ${ }^{1}$ and Joseph S. Beckman ${ }^{4}$ \\ ${ }^{1}$ Departamento de Neurobiología Celular y Molecular, Instituto de Investigaciones Biológicas Clemente Estable, Montevideo 11600, Uruguay, \\ ${ }^{2}$ Departamento de Histología and ${ }^{3}$ Departamento de Bioquímica, Facultad de Medicina, Universidad de la República, Montevideo 11800, Uruguay, and \\ ${ }^{4}$ Department of Biochemistry and Biophysics, Oregon State University, Linus Pauling Institute, Corvallis, Oregon 97331
}

\begin{abstract}
Nerve growth factor (NGF) can induce apoptosis by signaling through the p75 neurotrophin receptor (p75 ${ }^{\mathrm{NTR}}$ ) in several nerve cell populations. Cultured embryonic motor neurons expressing $\mathrm{p} 75^{\mathrm{NTR}}$ are not vulnerable to NGF unless they are exposed to an exogenous flux of nitric oxide ( $\mathrm{NO}$ ). In the present study, we show that $\mathrm{p} 75^{\mathrm{NTR}}$-mediated apoptosis in motor neurons involved neutral sphingomyelinase activation, increased mitochondrial superoxide production, and cytochrome $c$ release to the cytosol. The mitochondria-targeted antioxidants mitoQ and mitoCP prevented neuronal loss, further evidencing the role of mitochondria in NGF-induced apoptosis. In motor neurons overexpressing the amyotrophic lateral sclerosis (ALS)-linked superoxide dismutase $1^{\mathrm{G} 93 \mathrm{~A}}$ (SOD1 ${ }^{\mathrm{G} 93 \mathrm{~A}}$ ) mutation, $\mathrm{NGF}$ induced apoptosis even in the absence of an external source of ${ }^{\circ} \mathrm{NO}$. The increased susceptibility of SOD1 ${ }^{\mathrm{G} 93 \mathrm{~A}}$ motor neurons to NGF was associated to decreased nuclear factor erythroid 2-related factor 2 (Nrf2) expression and downregulation of the enzymes involved in glutathione biosynthesis. In agreement, depletion of glutathione in nontransgenic motor neurons reproduced the effect of SOD1 ${ }^{\text {G93A }}$ expression, increasing their sensitivity to NGF. In contrast, rising antioxidant defenses by Nrf2 activation prevented NGF-induced apoptosis. Together, our data indicate that $\mathrm{p} 75^{\mathrm{NTR}}$-mediated motor neuron apoptosis involves ceramide-dependent increased mitochondrial superoxide production. This apoptotic pathway is facilitated by the expression of ALS-linked SOD1 mutations and critically modulated by Nrf2 activity.
\end{abstract}

Key words: amyotrophic lateral sclerosis; mitochondria; motor neurons; nerve growth factor; Nrf2; $75^{\mathrm{NTR}}$; superoxide

\section{Introduction}

Nerve growth factor (NGF) has a key role on the development and function of the nervous system (Snider, 1994; Chao, 2003). In addition to promoting neuronal differentiation and survival, NGF can induce apoptosis of neurons during development and may also help eliminate damaged neurons and glial cells in pathological conditions (Barker, 2004; Nykjaer et al., 2005). NGF exerts its actions through two nonhomologous transmembrane receptors, the tyrosine kinase receptor TrkA and the p75 neurotrophin receptor $\left(\mathrm{p} 75^{\mathrm{NTR}}\right) \cdot \mathrm{p} 75^{\mathrm{NTR}}$ is a member of the tumor necrosis factor receptor superfamily and can act as a death receptor sig-

Received Feb. 22, 2007; revised June 3, 2007; accepted June 5, 2007.

This work was supported by the National Institutes of Health Fogarty International Research Collaboration Award R03TW006482 and Grants ES00040 and AT02034 (J.S.B. and L.B.); additional support was provided by Programa de Desarrollo de las Ciencias Básicas and Linus Pauling Institute. This work made use of the Cell Imaging and Mass Spectrometry Core Facilities of the Environmental Health Sciences Center (ES00210) sponsored by the National Institute of Environmental Health Sciences. We thank Drs. M. P. Murphy and B. Kalyanaraman for providing mito0 and mitoCP, respectively.

Correspondence should be addressed to Dr. Joseph S. Beckman, Linus Pauling Institute, Oregon State University, 571 Weniger Hall, Corvallis, 0R 97331-6512. E-mail: joe.beckman@oregonstate.edu. D0I:10.1523/JNEUROSCI.0823-07.2007

Copyright $@ 2007$ Society for Neuroscience $\quad$ 0270-6474/07/277777-09\$15.00/0 naling apoptosis in several neuronal populations (Barrett, 2000; Nykjaer et al., 2005).

Adult motor neurons had been thought to be unresponsive to NGF because they lack both TrkA and p75 receptors (Henderson et al., 1993; Yan et al., 1993; Sendtner et al., 2000). However, adult motor neurons can reexpress p75 ${ }^{\text {NTR }}$ after nerve injury (Koliatsos et al., 1991; Rende et al., 1995; Ferri et al., 1998) and in amyotrophic lateral sclerosis (ALS) (Seeburger et al., 1993; Lowry et al., $2001 \mathrm{~b})$. Induction of $\mathrm{p} 75^{\mathrm{NTR}}$ renders motor neurons vulnerable to NGF-induced apoptosis. $\mathrm{p} 75^{\mathrm{NTR}}$ has been implicated in motor neuron death occurring in transgenic mice overexpressing mutant $\mathrm{Cu}-\mathrm{Zn}$ superoxide dismutase (SOD1) (Lowry et al., 2001b; Copray et al., 2003; Kust et al., 2003; Turner et al., 2003a,b) or after axotomy (Ferri et al., 1998; Wiese et al., 1999; Lowry et al., 2001a). Pure motor neuron cultures expressing $\mathrm{p} 75^{\text {NTR }}$ are sensitive to NGF-induced apoptosis only when physiological concentrations of exogenous nitric oxide ( $\left.{ }^{\circ} \mathrm{NO}\right)$ are present, either from a $\mathrm{NO}$ donor or generated by feeder astrocyte monolayers (Pehar et al., 2004). These motor neurons also become immunoreactive for nitrotyrosine, suggesting that $\mathrm{p} 75^{\mathrm{NTR}}$ activation may be inducing a source of superoxide that converts nitric oxide into peroxynitrite.

Astrocytes can protect motor neurons against $\mathrm{p} 75^{\mathrm{NTR}}$ - 
induced apoptosis by the activation of the transcription factor nuclear factor erythroid 2-related factor 2 (Nrf2), which increases antioxidant defenses (Vargas et al., 2006). Thus, the signaling pathway induced by $\mathrm{p} 75^{\mathrm{NTR}}$ and its final outcome differs depending on the cell type and physiological context (Gentry et al., 2004; Nykjaer et al., 2005). The death pathway is not completely elucidated, but is associated with activation of c-Jun N-terminal kinase (JNK), release of cytochrome $c$ from mitochondria, and subsequent activation of caspases 9, 6, and 3 (Casaccia-Bonnefil et al., 1996; Yoon et al., 1998; Wang et al., 2001; Bhakar et al., 2003). Ceramide production may also be a mediator of $\mathrm{p} 75^{\text {NTR }}$ induced apoptosis (Dobrowsky et al., 1994; Casaccia-Bonnefil et al., 1996). Ceramide generation is dependent on either de novo ceramide synthesis and/or increased activity of sphingomyelinases, a family of enzymes distinguished by their different $\mathrm{pH}$ optima (Marchesini and Hannun, 2004). Ceramide could be a mediator of apoptosis by acting, directly or indirectly, on mitochondria, where it can dissipate the membrane potential, promote cytochrome $c$ release, and induce reactive oxygen species (ROS) production (Garcia-Ruiz et al., 1997; Gudz et al., 1997; Quillet-Mary et al., 1997; Mansat-de Mas et al., 1999; Birbes et al., 2002).

We have previously shown that $\mathrm{p} 75^{\mathrm{NTR}}$-induced motor neuron death involves increased production of ROS and reactive nitrogen species (RNS) (Pehar et al., 2004). However, the source of the increased ROS production induced by $\mathrm{p} 75^{\mathrm{NTR}}$ activation in motor neurons is currently unknown. In the present study, we investigated the apoptotic pathway mediated by $\mathrm{p} 75^{\mathrm{NTR}}$ in motor neurons and the impact of ALS-linked SOD $1{ }^{\text {G93A }}$ expression. We show that this pathway involved neutral sphingomyelinase (nSMase) activation and increased mitochondrial superoxide production. Motor neurons overexpressing ALS-linked SOD1 ${ }^{\text {G93A }}$ mutation showed greater susceptibility to the $\mathrm{p} 75^{\mathrm{NTR}}$-activated apoptotic pathway, which was associated to decreased Nrf2 expression and the consequent reduction in antioxidant defenses.

\section{Materials and Methods}

Materials. Culture media and serum were obtained from Invitrogen (Carlsbad, CA). Mouse NGF (2.5S) was obtained from Harlan (Madison, WI), recombinant human soluble Fas ligand and tertbutylhydroquinone (tBHQ) from Alexis (San Diego, CA), and primers from Integrated DNA Technologies (Coralville, IA). Blocking antibodies to NGF and $\mathrm{p} 75^{\mathrm{NTR}}$ were from Chemicon (Temecula, CA). Manumycin $\mathrm{A}$ and $N^{\prime}, N^{\prime}$-bis[4-(4,5-dihydro- $1 H$-imidazol-2-yl)phenyl]-3,3'-pphenylene-bis-acrylamide dihydrochloride (GW4869) were from Calbiochem (La Jolla, CA). All other reagents were from Sigma (St. Louis, MO) unless otherwise specified. Mitochondria-targeted ubiquinone (mitoQ) (Kelso et al., 2001) and carboxy proxyl (mitoCP) (Dhanasekaran et al., 2005) were kindly provided by Dr. M. P. Murphy (Medical Research Council-Dunn Human Nutrition Unit, Cambridge, UK) and Dr. B. Kalyanaraman (Medical College of Wisconsin, Milwaukee, WI), respectively.

Purified motor neuron cultures. Motor neuron cultures were prepared from embryonic day 15 (E15) rat spinal cord by a combination of metrizamide gradient centrifugation and immunopanning with the monoclonal antibody IgG192 against $\mathrm{p} 75^{\mathrm{NTR}}$ as described previously (Henderson et al., 1995). Transgenic SOD $1^{\mathrm{G} 93 \mathrm{~A}}$ and nontransgenic motor neurons were prepared in the same way, from E15 embryos genotyped by PCR. Sprague Dawley SOD $1{ }^{\text {G93A }}$ L26H rats were kindly provided by Dr. David S. Howland (Wyeth Research, Princeton, NJ) (Howland et al., 2002). Motor neurons were plated at a density of 350 cells $/ \mathrm{cm}^{2}$ on four-well multidishes or Lab-Tek (Nunclon; Nunc, Naperville, IL) precoated with polyornithine-laminin. Cultures were maintained in Neurobasal medium supplemented with $2 \%$ horse serum, $25 \mu \mathrm{M}$ L-glutamate, $25 \mu \mathrm{M}$ 2-mercaptoethanol, 0.5 mM L-glutamine, and 2\% B-27 supplement (In- vitrogen). Motor neuron survival was maintained by the addition of glial cell line-derived neurotrophic factor (GDNF) ( $1 \mathrm{ng} / \mathrm{ml}$; Sigma) to the culture media. Motor neuron death induced by trophic factor deprivation (NONE; without GDNF) was determined in all experiments as a control and never was $>50 \%$. Motor neuron survival was assessed after $48 \mathrm{~h}$ by direct counting of all cells displaying intact neurites longer than four cell bodies in diameter in a prefixed area of the dish. As a control, the expression of human SOD1 ${ }^{\mathrm{G} 93 \mathrm{~A}}$ was determined in the spinal cord of E15 embryos and in motor neuron cultures by Western blot. Briefly, protein samples from 30,000 motor neurons or $20 \mu \mathrm{g}$ of spinal cord extract were resolved on a $12 \%$ SDS-polyacrylamide gel and transferred to nitrocellulose membrane. Anti-SOD1 antibodies were developed in rabbit using recombinant pure human SOD1 as immunogen (kindly provided by Dr. M. Marin, University of the Republic, Montevideo, Uruguay). Membranes were reprobed with $\beta$-actin antibodies (Sigma) as a loading control.

Cell treatments. Treatments with NGF and inhibitors were performed $3 \mathrm{~h}$ after motor neuron plating unless otherwise specified. The generation of a steady-state concentration ( $<50 \mathrm{nM}$ ) of nitric oxide was obtained by the spontaneous disassociation of $10 \mu \mathrm{M}(2)-1$-[2-(2-aminoethyl)- $N-(2-$ ammonioethyl)amino]diazen-1-ium-1,2-diolate] (DETA-NONOate; Alexis). Soluble Fas ligand was added in the presence of enhancer antibody $(1 \mu \mathrm{g} / \mathrm{ml}) 16 \mathrm{~h}$ after motor neuron plating.

Treatment with antisense oligonucleotides to downregulate $\mathrm{p} 75^{\text {NTR }}$ expression in motor neurons was performed as described previously (Pehar et al., 2006). Briefly, HPLC-purified phosphorothioate antisense and missense oligonucleotides (5 $\mu \mathrm{M}$; Integrated DNA Technologies) were added to the cell suspension of purified motor neurons and repeatedly pipetted before seeding. The oligonucleotides were present the whole time of culture. To determine the efficiency of uptake, cultures were incubated with $\mathrm{p} 75^{\mathrm{NTR}}$ antisense oligonucleotides with a $5^{\prime} 56$ FAM fluorescent label. Cells were transferred to the heated stage $\left(37^{\circ} \mathrm{C}\right)$ of a Zeiss (Oberkochen, Germany) LSM510 confocal microscope with constant $5 \% \mathrm{CO}_{2}$. Fluorescence was imaged with a $63 \times$ oil immersion objective. Uptake efficiency was $>96 \%$ in all experiments. Sequences used were as follows: p75 ${ }^{\mathrm{NTR}}$ antisense, $5^{\prime}$-ACCTGCCCTCCTCATTGCA-3', and p75 ${ }^{\text {NTR }}$ missense, 5' -CTCCCACTCGTCATTCGAC-3' (Florez-McClure et al., 2004). This antisense sequence has previously been shown to be effective at inhibiting $\mathrm{p} 75^{\mathrm{NTR}}$-induced apoptosis in motor neurons both in vivo and in vitro (Lowry et al., 2001a; Pehar et al., 2006).

Relative quantitative reverse transcription-PCR. RNA was extracted from purified motor neuron cultures using RNeasy (Qiagen, Valencia, CA) and cDNA was prepared using SuperScript II retrotranscriptase (Invitrogen) according to manufacturer's instructions. PCR primers specific to each gene are as follows: Nrf2, 5' -TTCCTCTGCTGCCATTAGTCAGTC- ${ }^{\prime}$, and $5^{\prime}$-GCTCTTCCATTTCCGAGTCACTG-3' (242 bp); glutamate-cysteine ligase modifier subunit (GCLM), 5'-AATCTTGCCTCCTGCTGTGTGATG-3' , and 5'-GGCTTCAATGTCAGGGATGCTTTC-3' (153 bp); glutamate-cysteine ligase catalytic subunit (GCLC), 5'-ATGAAAGTGGCACAGGAGCGAG-3', and 5'-AAACACGCCTTCCTTCCCATTG-3' (186 bp); neuronal nitric oxide synthase (nNOS), 5' -CCACACCAACGGGAATCAGGAG-3', and 5'-TCCTCCAGCACCTCCACCATTG-3' (405 bp); actin, 5'-CATGAAGATCCTGACCGAGCGTG-3', and 5' ${ }^{\prime}$-TCTGCTGGAAGGTGGACAGTGAGG-3' (497 bp). p75 ${ }^{\text {NTR }}$ primers were from Promega (Madison, WI). PCRs were performed in a $50 \mu \mathrm{l}$ reaction volume containing $5 \mu \mathrm{l}$ of cDNA, 20 pmol of each specific primer, $200 \mu \mathrm{M}$ dNTPs, $2.5 \mathrm{~mm} \mathrm{MgCl}_{2}$, $1.5 \mathrm{U}$ of AmpliTaq Gold, and $1 \times$ GeneAmp PCR buffer (Applied Biosystems, Foster City, CA). Minus reverse transcription (RT) controls were included in each assay and control reactions were run to ensure the amplification was in the linear range. The amplification products were separated in non-denaturing $6 \%$ polyacrylamide gel and stained with SYBR Gold Nucleic Acid Gel Stain (Invitrogen). Densitometric analysis was performed using the NIH Image program, and gene expression levels were normalized against actin levels.

Fluorescence emission of reactive probes. To test fluorescence emission of MitoSOX Red (mito-HE; Invitrogen), $24 \mathrm{~h}$ plated motor neurons were transferred to the heated stage $\left(37^{\circ} \mathrm{C}\right)$ of a Zeiss LSM510 confocal micro- 
scope with constant $5 \% \mathrm{CO}_{2}$. Fluorescence was imaged using a $405 \mathrm{~nm}$ diode laser with a $63 \times$ oil immersion objective with objective heater. The microscope was kept centered on one set of cells throughout an experiment. Before treatment with mito-HE, instrument parameters were set to minimize autofluorescence at $405 \mathrm{~nm}$. Afterward, laser and image intensities were kept constant. Cells were incubated with $0.1 \mu \mathrm{M}$ mito-HE for $15 \mathrm{~min}$ and after washing incubated in supplemented L15 (Pehar et al., 2004) without phenol red. Images were obtained immediately after mito-HE treatment and then every $10 \mathrm{~min}$. No increase in mito-HE fluorescence was observed in control conditions. Alternatively, after mito-HE incubation, cells were treated with $100 \mathrm{ng} / \mathrm{ml} \mathrm{NGF}$ and then imaged every $15 \mathrm{~min}$. Treatment with GW4869 (100 nM) was performed $3 \mathrm{~h}$ after motor neuron plating and fluorescence was analyzed $24 \mathrm{~h}$ later. Immediately after mito-HE fluorescence analysis, cells were incubated with the mitochondrial probe Mitotracker Deep Red (3.6 nM; Invitrogen) to confirm colocalization with mito-HE (data not shown). The Zeiss LSM510 image analysis software package was used to quantify fluorescence in motor neuron cultures.

To test monochlorobimane fluorescence emission, motor neurons maintained with GDNF (1 ng/ml) were treated with buthioninesulfoximine (BSO) $(10 \mathrm{~nm})$ or tBHQ (500 nM). After $24 \mathrm{~h}$, cells were incubated for $30 \mathrm{~min}$ in culture medium with monochlorobimane (10 $\mu \mathrm{M})$ and fixed in ice-cold $4 \%$ paraformaldehyde, $0.1 \%$ glutaraldehyde in PBS. Fluorescence was imaged by confocal microscopy immediately after fixing.

Cytochrome c immunolabeling. Nontransgenic and SOD1 ${ }^{\mathrm{G} 93 \mathrm{~A}}$ motor neuron cultures were maintained for $16 \mathrm{~h}$ in the presence of GDNF ( 1 $\mathrm{ng} / \mathrm{ml})$ and then treated with NGF $(100 \mathrm{ng} / \mathrm{ml})$ in the presence or absence of DETA-NONOate $(10 \mu \mathrm{m})$. After $12 \mathrm{~h}$, cultures were fixed as described above and processed for cytochrome $c$ immunolabeling using Alexa Fluor 488 cytochrome $c$ apoptosis detection kit from Invitrogen. Imaging was performed by confocal microscopy, and the percentage of cells with diffuse staining was determined.

Statistical analysis. Data analysis was performed using standard statistical packages (SigmaStat; Jandel, San Rafael, CA). All values are the mean of at least three independent experiments performed in duplicate. Comparison of the means was performed by one-way ANOVA. Pairwise contrast between means used the Student-Newman-Keuls test and differences were declared statistically significant if $p<0.05$.

\section{Results}

Because increased ceramide production has been involved as a central component of the apoptotic pathway mediated by p $75^{\text {NTR }}$ in other cell types, we examined its role in p75 ${ }^{\text {NTR }}$ mediated motor neuron apoptosis. Consistent with our previous results (Pehar et al., 2004), NGF reduced motor neuron survival by $40 \%$ only in the presence of the nitric oxide ( $\mathrm{NO}$ ) donor DETA-NONOate $\left(10 \mu \mathrm{m}\right.$; steady-state concentration of ${ }^{\circ} \mathrm{NO}$, $<50 \mathrm{nM}$ ), whereas $\mathrm{NO}$ alone did not affect neuronal survival (Fig. 1A). The extent of NGF-induced reduction in motor neuron survival was similar to that induced by trophic factor deprivation $(44 \pm 6.1 \%$ ) (Fig. $1 A$, dashed lines). NGF-induced motor neuron death was blocked by manumycin A (10 nM) and GW4869 (100 nM), specific inhibitors of nSMase (Arenz et al., 2001; Luberto et al., 2002) (Fig. 1A). However, desipramine (5 nM to $5 \mu \mathrm{M}$ ), an inhibitor of the acid isoform of SMase was devoid of effect (Fig. 1A). These results indicate the involvement of ceramide production by nSMase activation in $\mathrm{p} 75^{\mathrm{NTR}}$-mediated motor neuron apoptosis.

Immunofluorescence studies revealed that nSMase activation was followed by cytochrome $c$ release from mitochondria (Fig. $1 B)$. In the absence of NGF, motor neurons showed a punctate pattern of cytochrome $c$ immunoreactivity, indicative of mitochondrial localization. NGF (100 ng/ml) or DETA-NONOate (10 $\mu \mathrm{M})$ treatment alone did not affect cytochrome $c$ localization (Fig. 1C). In contrast, after $12 \mathrm{~h}$ of NGF treatment in the presence
$\mathbf{A}$

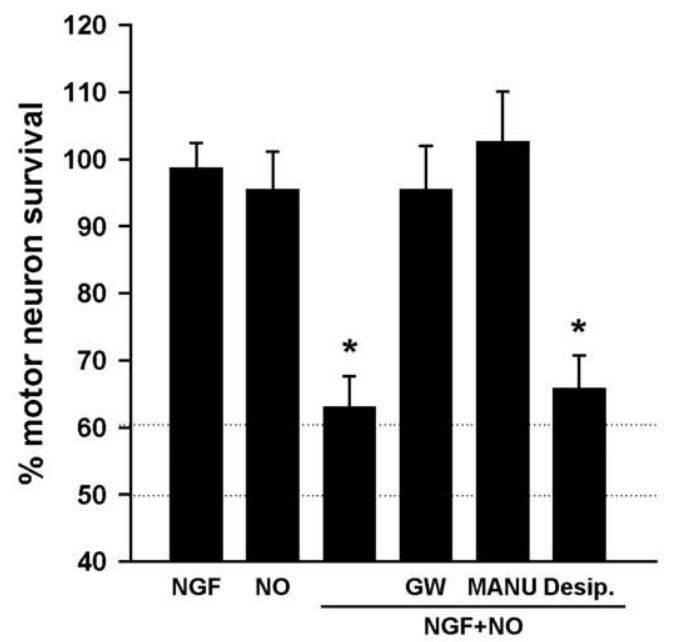

B
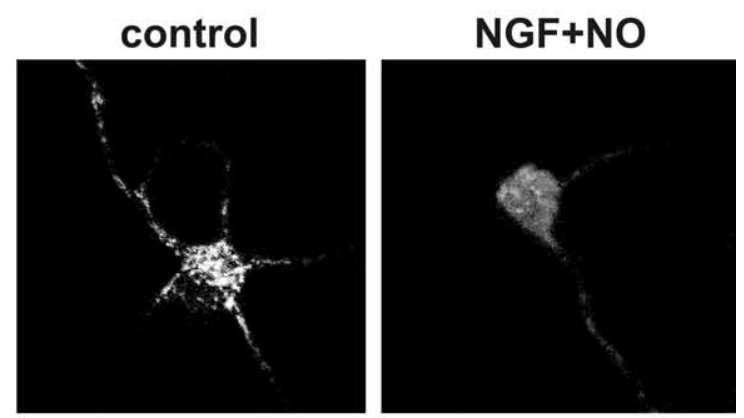

C

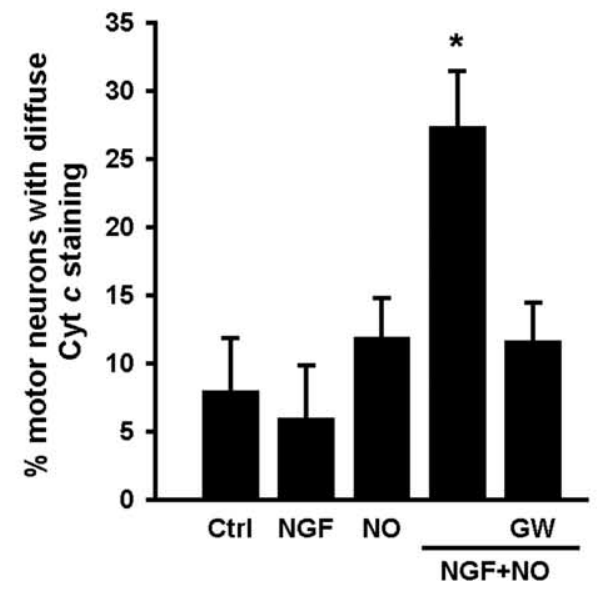

Figure 1. NGF-induced apoptosis in motor neurons involves nSMase activation and triggers cytochrome crelease from mitochondria. $A$, Pure motor neuron cultures maintained with GDNF $(1 \mathrm{ng} / \mathrm{ml})$ were exposed to NGF (100 ng/ml) plus $10 \mu \mathrm{m}$ DETA-NONOate (yielding $\sim 50 \mathrm{~nm}{ }^{\circ}$ N0 steady state) in the presence of vehicle, GW4869 (100 nm; GW), manumycin A (10 nm; MANU), or desipramine (5 $\mu \mathrm{m}$; Desip.). SMase inhibitors were added $1 \mathrm{~h}$ before NGF and DETA-NONOate. Motor neuron survival was determined $48 \mathrm{~h}$ after treatment. The dashed lines represent the SD of trophic factor deprivation (NONE; without GDNF) as a control for maximum cell death observed. Data are expressed as percentage of GDNF (mean \pm SD). * $p<0.05$, significantly different from GDNF. $B$, Fluorescence microphotographs showing cytochrome c immunoreactivity in motor neurons maintained with GDNF (control) or exposed to NGF plus DETA-NONOate (NGF+NO). In the absence of NGF, motor neurons showed a punctuate (mitochondrial) labeling of cytochrome $c$, whereas $12 \mathrm{~h}$ after treatment with NGF+NO motor neurons showed a diffuse cytoplasmic labeling. C, GW4869 (100 nM; GW) prevented cytochrome c release induced by NGF+NO. Motor neurons maintained with GDNF ( $1 \mathrm{ng} / \mathrm{ml})$ were exposed to vehicle (Ctrl), NGF (100 ng/ml), DETA-NONOate (10 $\mu \mathrm{m}$; N0), GW4869 (100 nm; GW), or its combination. The percentage of motor neurons showing diffuse labeling was determined by direct counting under the microscope. GW alone did not affect cytochrome c labeling (data not shown). ${ }^{*} p<0.05$, significantly different from control. 
A
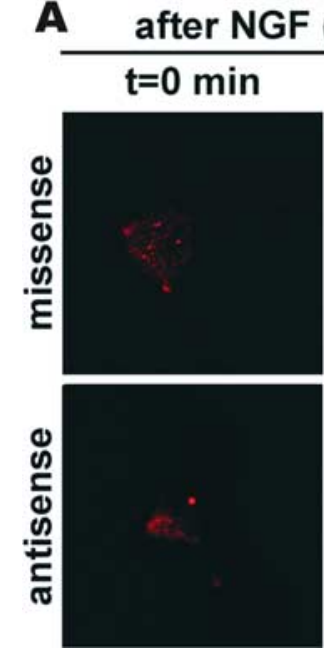

(100 ng/ml) $\mathrm{t}=\mathbf{4 0} \mathrm{min}$
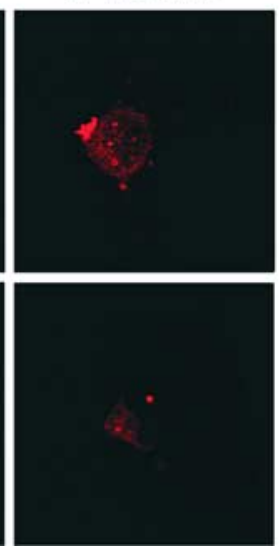

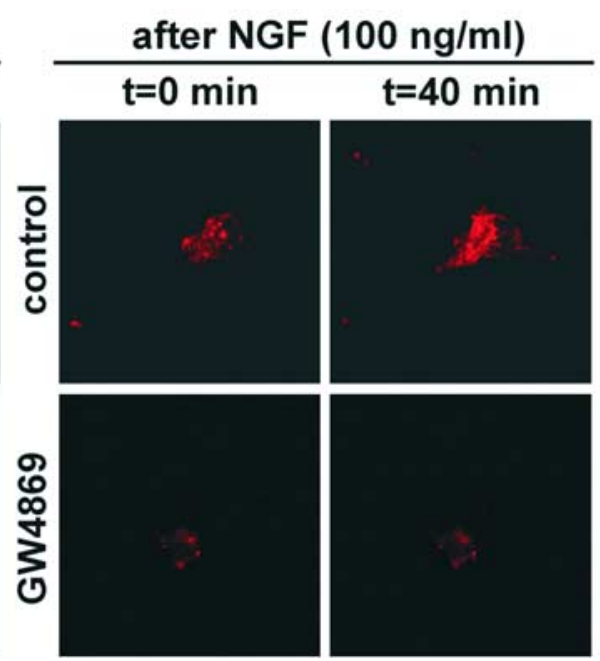

B

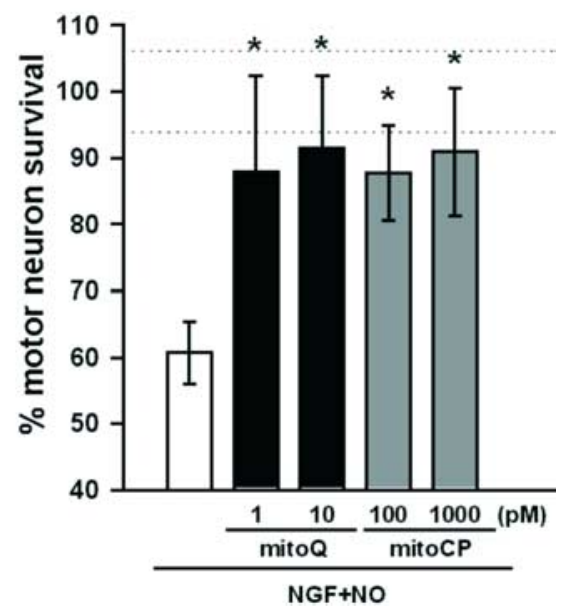

Figure 2. NGF increases superoxide production by mitochondria. $\boldsymbol{A}$, Superoxide production by mitochondria was analyzed using MitoSOX Red (mito-HE). Motor neurons cultures were incubated for 15 min with $0.1 \mu \mathrm{m}$ mito-HE and after washing were exposed to NGF ( $100 \mathrm{ng} / \mathrm{ml})$. Microphotographs show the fluorescence emission of mito-HE ( $\left.\lambda_{\text {exc' }} 405 \mathrm{~nm}\right)$ immediately after NGF addition $(t=0 \mathrm{~min}$ ) and $40 \mathrm{~min}$ later $(t=40 \mathrm{~min}$ ). Fluorescence emission did not change after $40 \mathrm{~min}$ in cultures maintained with GDNF in the absence of NGF (data not shown). The increased mito-HE fluorescence emission induced by NGF was not observed in cultures preincubated for $24 \mathrm{~h}$ with antisense oligonucleotides to downregulate p75 ${ }^{\mathrm{NTR}}$ expression or GW4869 (100 nM). Preincubation with missense oligonucleotides did not prevent the effect of NGF. B, Motor neuron cultures maintained with GDNF (1 ng/ml) were exposed to NGF (100 ng/ml) plus DETA-NONOate (10 $\mu$ m) (NGF $+N 0$ ) in the presence of vehicle (white bar) or the indicated concentrations of mito Q or mitoCP. The dashed lines represent the SD of GDNF. Data are expressed as percentage of GDNF (mean \pm $\mathrm{SD}) .{ }^{*} p<0.05$, significantly different from NGF+NO.

of DETA-NONOate, $\sim 27 \%$ of motor neurons displayed a diffuse pattern of cytochrome $c$ immunoreactivity, indicating release into the cytoplasm (Fig. $1 B, C$ ). Cytochrome $c$ release induced by NGF in the presence of nitric oxide was prevented by the addition of the nSMase inhibitor GW4869 (Fig. 1C), indicating that cytochrome $c$ release required ceramide production.

It has been previously shown that ceramide may induce ROS production by mitochondria (Garcia-Ruiz et al., 1997; QuilletMary et al., 1997; Mansat-de Mas et al., 1999). We therefore tested for the potential involvement of mitochondrial ROS production in NGF-mediated motor neuron death. Superoxide $\left(\mathrm{O}_{2}^{\bar{*}}\right)$ production by mitochondria was analyzed using MitoSOX Red (mito-HE). Mito-HE comprises HE (hydroethidine), a commonly used probe for $\mathrm{O}_{2}^{-}$, covalently linked to the lipophilic $\mathrm{TPP}^{+}$(triphenylphosphonium cation), which selectively target molecules to mitochondria. The oxidation of mito-HE by $\mathrm{O}_{2}^{-}$ generates a hydroxylated product that can be selectively excited at $396 \mathrm{~nm}$ to specifically detect $\mathrm{O}_{\dot{2}}^{-}$production (Robinson et al., 2006). Mito-HE fluorescence was analyzed in pure motor neuron cultures by confocal microscopy using $405 \mathrm{~nm}$ excitation. NGF $(100 \mathrm{ng} / \mathrm{ml})$ treatment induced a $1.7 \pm 0.2$-fold increase in mito-HE fluorescence emission (Fig. $2 \mathrm{~A}$ ), whereas no change in fluorescence emission was observed after $40 \mathrm{~min}$ in control experiments treated with vehicle (data not shown). The increase in mito-HE fluorescence emission was prevented by downregulation of $\mathrm{p} 75^{\mathrm{NTR}}$ expression by antisense treatment or preincubation of motor neurons with the nSMase inhibitor GW4869 (100 nM) (Fig. $2 \mathrm{~A}$ ), suggesting that increased $\mathrm{O}_{2}^{-}$production by mitochondria follows $\mathrm{p} 75^{\mathrm{NTR}}$ and nSMase activation. Moreover, the mitochondria-targeted antioxidants mitoQ and mitoCP at concentrations in the picomolar range (Kelso et al., 2001; Dhanasekaran et al., 2005) also blocked NGF-induced motor neuron death (Fig. $2 B$ ), strengthening the role of ROS production by mitochondria in $\mathrm{p} 75^{\mathrm{NTR}}$-mediated motor neuron apoptosis.

In contrast to nontransgenic motor neurons, SOD $1^{\mathrm{G} 93 \mathrm{~A}}$ expressing motor neurons were sensitive to NGF-induced apoptosis in the absence of the nitric oxide donor DETA-NONOate even at concentrations of $10 \mathrm{ng} / \mathrm{ml} \mathrm{NGF}$ (Fig. 3). The expression of SOD $1^{\mathrm{G} 93 \mathrm{~A}}$ in transgenic motor neurons under our culture conditions was confirmed by Western blot and found to be significantly higher than the endogenous rat SOD1. Curiously, the presence of DETA-NONOate $(10 \mu \mathrm{M})$, which renders nontransgenic motor neurons sensitive to NGF-induced apoptosis, did not further decrease the survival of SOD $1{ }^{\mathrm{G} 93 \mathrm{~A}}$-expressing motor neurons (Fig. 3A). NGF-induced apoptosis in SOD $1^{\mathrm{G} 93 \mathrm{~A}}$ expressing motor neurons was prevented by blocking antibodies to $\mathrm{p} 75^{\mathrm{NTR}}$ ( $93 \pm 6 \%$ of control). The effectiveness of the $\mathrm{p} 75^{\mathrm{NTR}}$ blocking antibodies to prevent signaling through $\mathrm{p} 75^{\mathrm{NTR}}$ in motor neuron cultures has been previously established (Pehar et al., 2004). Moreover, p $75^{\mathrm{NTR}}$-mediated apoptosis in SOD ${ }^{\mathrm{G} 93 \mathrm{~A}}$ motor neurons was prevented by nSMase inhibitors (Fig. 3B) and involved mitochondrial $\mathrm{O}_{2}^{-}$production and cytochrome $c$ release (Fig. $3 C, D$ ). In addition, the mitochondria-targeted antioxidants mitoQ (10 pM) and mitoCP (1 nM) also prevented NGF-induced apoptosis in SOD1 ${ }^{\mathrm{G} 93 \mathrm{~A}}$ motor neurons (Fig. $3 E$ ). Although an exogenous source of nitric oxide is not required for NGF to induce SOD $1{ }^{\mathrm{G} 93 \mathrm{~A}}$ motor neuron death, $N$-nitro-L-arginine methyl ester (NAME) (1 mM), a general nitric oxide synthase (NOS) inhibitor, and 1-(2-trifluoromethylphenyl)imidazole (TRIM) $(10 \mu \mathrm{M})$, a specific inhibitor of the neuronal isoform of NOS, prevented NGF-induced apoptosis in SOD $1{ }^{\mathrm{G} 93 \mathrm{~A}}$ motor neurons (Fig. 3E). These results indicate that the apoptotic pathway induced by NGF in SOD1 ${ }^{\text {G93A }}$ motor neurons required endogenous nitric oxide production by nNOS activation.

The increased sensitivity of SOD $1{ }^{\mathrm{G} 93 \mathrm{~A}}$ motor neurons to NGF could not be explained by differential expression of $\mathrm{p} 75^{\mathrm{NTR}}$ or nNOS. No significant difference was observed in $\mathrm{p} 75^{\mathrm{NTR}}$ and nNOS mRNA expression levels between nontransgenic and SOD1 ${ }^{\text {G93A }}$ motor neurons as determined by RT-PCR (data not shown). However, a $30 \%$ decrease in the expression of the transcription factor Nrf2 was observed in SOD1 ${ }^{\mathrm{G} 93 \mathrm{~A}}$ motor neurons compared with nontransgenic ones (Fig. 4). The decrease in Nrf2 expression correlated with a decrease in the expression of $\mathrm{Nrf} 2$ regulated genes, including both subunits of glutamate-cysteine 


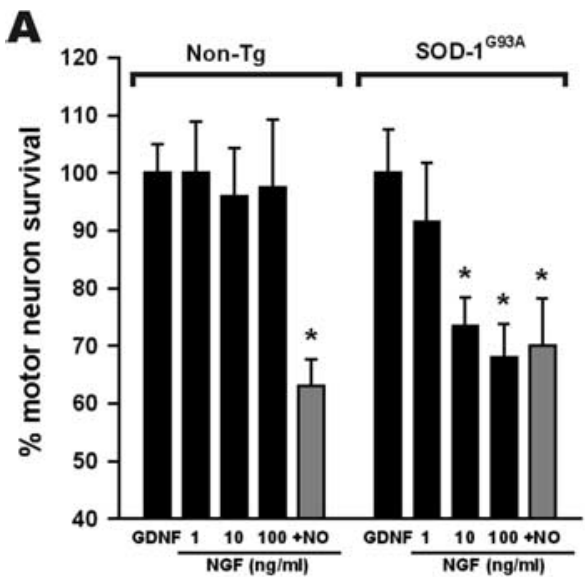

C
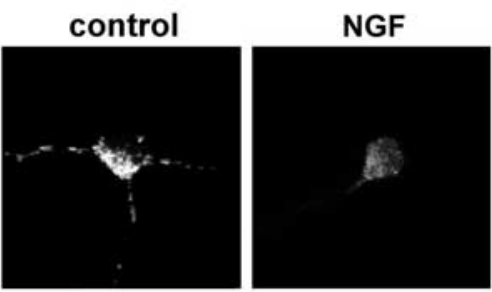

E

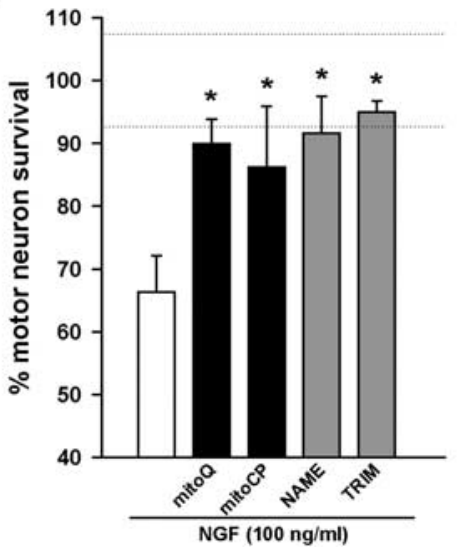

$\mathbf{B}$

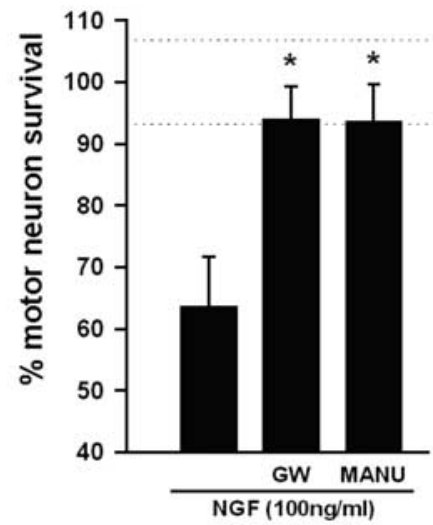

D

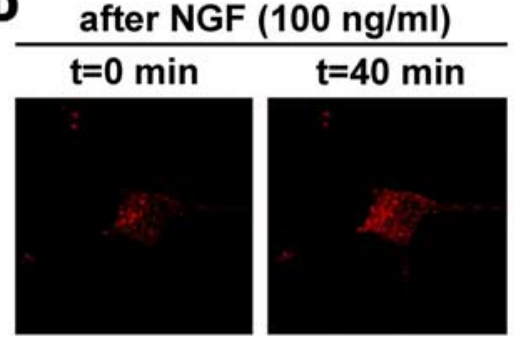

$\mathbf{F}$
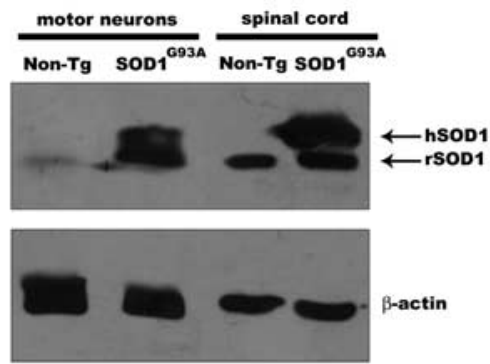

Figure 3. Motor neurons overexpressing SOD ${ }^{693 A}$ show increase susceptibility to NGF-induced apoptosis. $\boldsymbol{A}$, Motor neurons isolated from SOD $1{ }^{\text {G93A }}$ or nontransgenic (Non-Tg) E15 embryos were maintained in the presence of GDNF ( $1 \mathrm{ng} / \mathrm{ml}$ ) and exposed to increasing concentrations of NGF. The gray bars represent motor neuron survival in cultures exposed to NGF ( $100 \mathrm{ng} / \mathrm{ml})$ in the presence of DETA-NONOate $\left(10 \mu \mathrm{M}\right.$ ). Data are expressed as percentage of its respective GDNF condition (mean $\pm \mathrm{SD}$ ). ${ }^{*} p<0.05$, significantly different from GDNF. B, SOD $1{ }^{\mathrm{G} 93 \mathrm{~A}}$ transgenic motor neurons were exposed to NGF in the presence of vehicle, GW4869 ( $100 \mathrm{~nm} ; \mathrm{GW})$ or manumycin A (10 nм; MANU). The dashed lines represent the SD of GDNF. Data are expressed as percentage of GDNF (mean $\pm \mathrm{SD}$ ). ${ }^{*} p<0.05$, significantly different from NGF. C, Fluorescence microphotographs showing cytochrome $C$ immunoreactivity in SOD1 ${ }^{693 \mathrm{~A}}$ motor neurons maintained with GDNF and exposed to vehicle (control) or NGF ( $100 \mathrm{ng} / \mathrm{ml}$ ). In the absence of NGF, motor neurons showed a punctuate labeling of cytochrome $c$, and $12 \mathrm{~h}$ after treatment with NGF a diffuse labeling was observed in affected motor neurons. $D$, Microphotographs show the fluorescence emission of mito-HE $\left(\lambda_{\text {exc }}, 405 \mathrm{~nm}\right)$ in $\mathrm{SOD}^{\mathrm{G}}{ }^{\mathrm{G} 3 \mathrm{~A}}$ motor neurons immediately after NGF addition $(t=0 \mathrm{~min})$ and $40 \mathrm{~min}$ later $(t=40 \mathrm{~min})$. Motor neuron cultures were treated as described in Figure 2.E, $S O D 1^{693 A}$ transgenic motor neurons were exposed to NGF in the presence of vehicle, mito $Q$ (10 $\mathrm{pM})$, mitoCP (1 nM), NAME (1 mM), or TRIM $(10 \mu \mathrm{M})$. Motor neuron survival was determined $48 \mathrm{~h}$ later. The dashed lines represent the SD of GDNF. Data are expressed as percentage of GDNF (mean $\pm S D$ ). ${ }^{*} p<0.05$, significantly different from NGF. $F$, Western blot showing the expression of human mutant SOD1 (hSOD1) in the spinal cord and isolated motor neurons from transgenic ALS mice embryos. Only the endogenous rat SOD1 (rSOD1) was detected in either the spinal cord or motor neurons isolated from nontransgenic (Non-Tg) embryos.

ligase (GCL), GCLC and GCLM, the rate-limiting enzyme in reduced glutathione (GSH) biosynthesis (Fig. 4). In agreement, inhibition of GSH synthesis by treatment with BSO (10 nM) increased the sensitivity of nontransgenic motor neurons to NGF
(Fig. 5A). Nontransgenic motor neurons previously exposed to BSO were sensitive to NGF-induced apoptosis even in the absence of DETA-NONOate (Fig. 5A). The concentration of BSO used (10 nM) did not affect motor neuron survival by itself but decreased GSH levels as evidenced by the fluorescent probe monochlorobimane (Fig. $5 A$ ). In contrast, $\mathrm{tBHQ}$ treatment, a well known Nrf2 activator in neurons (Johnson et al., 2002), completely prevented motor neuron death induced by NGF in the presence of ${ }^{\circ} \mathrm{NO}$ (Fig. $5 B$ ). Increased GSH content in motor neurons after tBHQ treatment was confirmed by monochlorobimane fluorescence emission (Fig. 5B, top panel).

Nrf2 activation by tBHQ also prevented NGF-induced apoptosis in SOD $1{ }^{\text {G93A }}$ motor neurons (Fig. 6A). To determine whether augmented antioxidant defenses also protect neurons from apoptosis triggered by other death receptors, we analyzed the effect of tBHQ on apoptosis induced by Fas ligand in SOD $1{ }^{\mathrm{G} 93 \mathrm{~A}}$-expressing motor neurons. Rat SOD ${ }^{\mathrm{G} 93 \mathrm{~A}}$ motor neurons also displayed increased sensitivity to Fas-mediated apoptosis (Fig. 6B), in agreement with a previous report by Raoul et al. (2002) in mouse motor neurons. The soluble extracellular domain of Fas ligand ( $\mathrm{sFasL}$ ) in the presence of an enhancer antibody significantly reduced the survival of motor neurons in a dose-response manner, whereas the enhancer antibody alone did not affect neuronal survival (data not shown). However, the reduction of motor neuron survival induced by sFasL was higher in SOD $1{ }^{\mathrm{G} 93 \mathrm{~A}}$ cultures than in nontransgenic, reaching a plateau at concentrations $>0.5$ ng/ml (Fig. 6B). Remarkably, tBHQ treatment also prevented motor neuron death induced by sFasL (Fig. 6B).

\section{Discussion}

Reexpression of $\mathrm{p} 75^{\mathrm{NTR}}$ under pathological conditions renders motor neurons vulnerable to NGF (Ferri et al., 1998; Wiese et al., 1999; Lowry et al., 2001a). In the present study, we show that the NGF/ p $75^{\mathrm{NTR}}$-mediated motor neuron apoptosis involved increased production of mitochondrial superoxide and could be prevented by increasing neuronal antioxidant defenses. Moreover, ALS-linked SOD1 ${ }^{\mathrm{G} 93 \mathrm{~A}}$ overexpression increases motor neuron vulnerability to NGF-mediated apoptosis by reducing antioxidant defenses. Such effect could be explained not only by the expression of $\mathrm{SOD} 1{ }^{\mathrm{G} 93 \mathrm{~A}}$ with aberrant redox properties (Beckman et al., 2001) but also by reduced Nrf2 expression, which leads to a downregulation of the key enzymes involved in 
GSH biosynthesis. In accordance, pharmacological activation of Nrf2 prevented $\mathrm{NGF} / \mathrm{p} 75^{\mathrm{NTR}}$-induced motor neuron apoptosis, suggesting a potential target to counteract $\mathrm{p} 75^{\mathrm{NTR}}$-mediated motor neuron death occurring in pathological conditions.

p $75^{\text {NTR }}$ induces cell death by activating different signaling pathways, depending on the cell type and physiological context (Gentry et al., 2004; Nykjaer et al., 2005). As observed for other apoptotic stimuli, including trophic factor deprivation and Fas (Estévez et al. 1998; Raoul et al., 2002), the mechanism of p $75^{\mathrm{NTR}}$-induced apoptosis in motor neurons involves downstream production of nitric oxide and peroxynitrite formation (Pehar et al., 2004). In the present study, we found that the p $75^{\text {NTR }}$ apoptotic pathway in motor neurons involved increased ceramide production and cytochrome $c$ release into the cytosol, as observed in other cell types (Casaccia-Bonnefil et al., 1996; Kuner and Hertel, 1998; Brann et al., 2002; Bhakar et al., 2003). p75 ${ }^{\text {NTR }}$-induced ceramide generation in motor neurons was mediated by activation of the neutral isoform of SMase. A similar p $75^{\mathrm{NTR}}$-mediated apoptotic pathway was described previously in hippocampal neurons, involving nSMase activation, increased ceramide generation, and subsequent JNK activation (Brann et al., 2002). However, in p $75^{\mathrm{NTR}}$-expressing NIH-3T3 and PC12 cell lines, the acid isoform of SMase has been implicated in ceramide production induced by $\mathrm{p} 75^{\mathrm{NTR}}$ signaling (Dobrowsky and Carter, 1998). Thus, it seems that $\mathrm{p} 75^{\mathrm{NTR}}$ is able to activate different SMases depending on the cell type. Interestingly, the spinal cord of ALS patients and SOD $1{ }^{\text {G93A }}$ mice exhibit a remarkable increase in ceramides and cholesterol esters, which have been shown to sensitize motor neurons to different death stimuli including oxidative and excitotoxic insults (Cutler et al., 2002). Therefore, NGF signaling through $\mathrm{p} 75^{\mathrm{NTR}}$ and the subsequent increase in ceramide production may also modulate the sensitivity of motor neurons to other apoptotic stimuli.

In motor neurons, ceramide generation induced by $\mathrm{p} 75^{\mathrm{NTR}}$ signaling increased superoxide production by mitochondria as evidenced by oxidation of mito-HE monitored at a more selective wavelength (Robinson et al., 2006). These results reveal mitochondria are an important source of superoxide in motor neurons exposed to NGF. It is noteworthy that the increased superoxide production by mitochondria does not require nitric oxide, whereas cytochrome $c$ release does require the presence of an external source of nitric oxide, such as the addition of DETA-NONOate. These results suggest that peroxynitrite, a strong oxidant formed from the reaction of super-
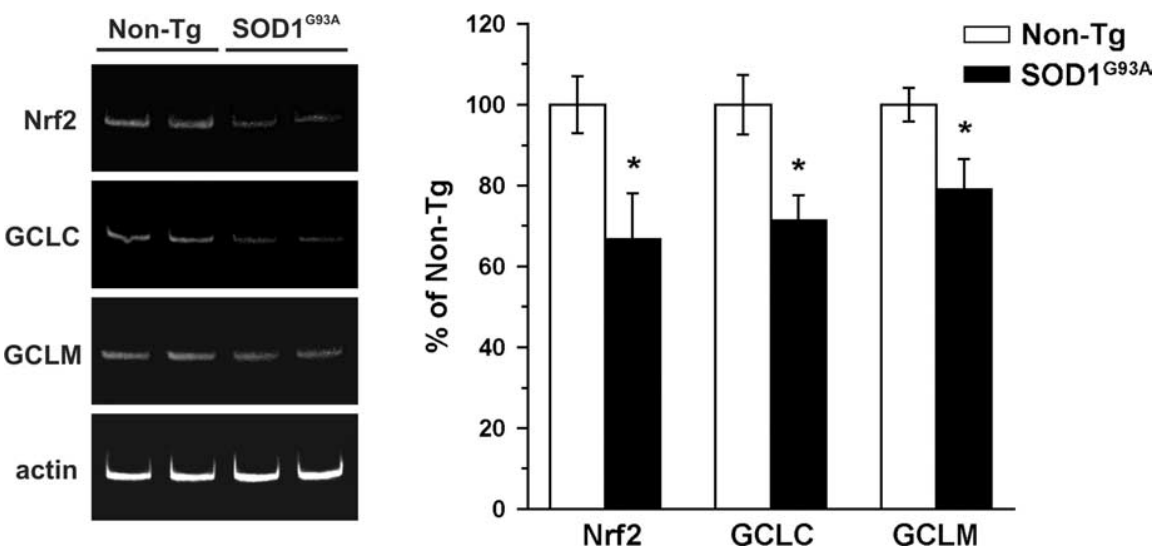

Figure 4. Reduced antioxidant defenses in SOD1 ${ }^{693 \mathrm{~A}}$ motor neurons. SOD1 ${ }^{693 \mathrm{~A}}$ and nontransgenic (Non-Tg) motor neuron cultures were maintained with GDNF ( $1 \mathrm{ng} / \mathrm{ml}$ ) for $24 \mathrm{~h}$, and the expression level of Nrf2, GCLC, and GCLM mRNA was determined by relative quantitative RT-PCR as described in Materials and Methods. mRNA levels were corrected by actin mRNA amplification and are expressed as percentage of nontransgenic. ${ }^{*} p<0.05$, significantly different from nontransgenic.
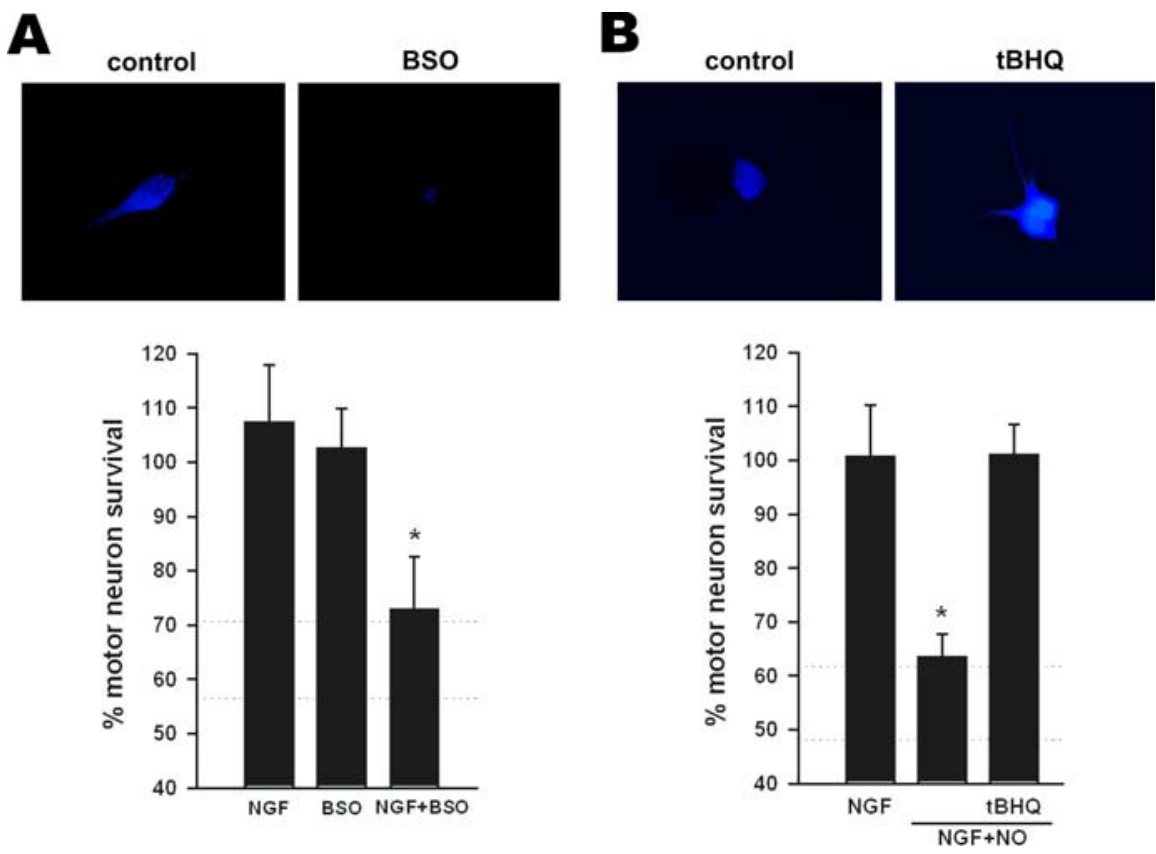

Figure 5. Glutathione levels modulate NGF-induced motor neuron apoptosis. $\boldsymbol{A}$, Nontransgenic motor neuron cultures were incubated with vehicle or BSO (10 nm) and $24 \mathrm{~h}$ later were exposed to NGF $(100 \mathrm{ng} / \mathrm{ml})$. Motor neuron survival was determined $48 \mathrm{~h}$ after NGF treatment. NGF did not affect motor neuron survival in cultures preincubated with vehicle. BSO did not affect motor neuron survival by itself. The dashed lines represent the SD of NONE. Data are expressed as percentage of GDNF (mean \pm SD). ${ }^{*} p<0.05$, significantly different from GDNF. The top panel shows monochlorobimane fluorescence emission from cultures maintained with GDNF (1 ng/ml) and treated for $24 \mathrm{~h}$ with vehicle (control) or BSO. B, Microphotographs show increased monochlorobimane fluorescence caused by increased GSH content in motor neuron cultures treated for $24 \mathrm{~h}$ with tBHQ ( $500 \mathrm{~nm})$ compared with vehicle (control). tBHQ prevented motor neuron death induced by NGF ( $100 \mathrm{ng} / \mathrm{ml})$ plus DETA-NONOate (10 $\mu \mathrm{m}$; $\mathrm{NGF}+\mathrm{NO}$ ). Data are expressed as percentage of GDNF (mean $\pm \mathrm{SD}$ ). The dashed lines represent the SD of NONE. ${ }^{*} p<0.05$, significantly different from GDNF.

oxide and nitric oxide, disrupts mitochondrial function to promote cytochrome $c$ release (Beckman and Koppenol, 1996; Radi et al., 2002). We have previously shown that superoxide and peroxynitrite scavengers completely prevent motor neuron death induced by NGF through p75 NTR (Pehar et al., 2004). Moreover, the prevention of motor neuron loss by mitochondria-targeted ubiquinone (mitoQ) or carboxy proxyl (mitoCP) supports a role for mitochondrial oxidative damage in NGF-mediated apoptosis. The selective accumulation and constant recycling by mitochondria make these antioxidants 500 - to 800 -fold more active than 


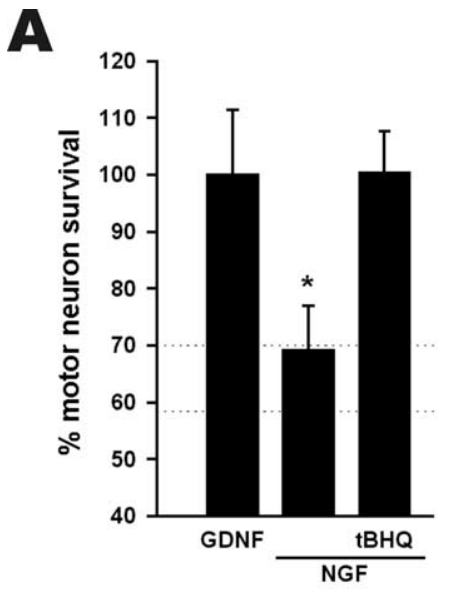

B

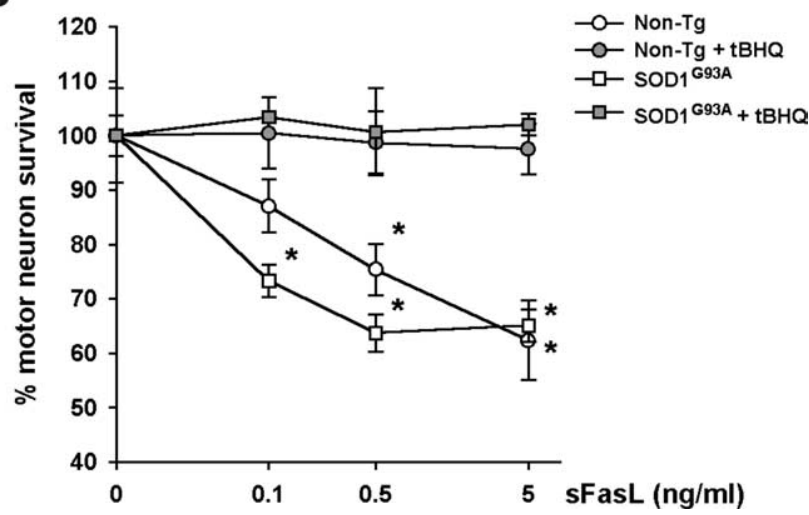

Figure 6. Increased Nrf2 activation prevents $\mathrm{SOD} 1{ }^{693 \mathrm{~A}}$ motor neuron death induced by NGF or SFasL. $A, S O D 1{ }^{693 A}$ motor neuron cultures maintained with $\operatorname{GDNF}(1 \mathrm{ng} / \mathrm{ml})$ were exposed to NGF $(100 \mathrm{ng} / \mathrm{ml})$ in the presence of vehicle or $\mathrm{ABHQ}(500 \mathrm{~nm})$. Motor neuron survival was determined $48 \mathrm{~h}$ after treatment. The dashed lines represent the SD of NONE. Data are expressed as percentage of GDNF (mean \pm SD). ${ }^{*} p<0.05$, significantly different from GDNF. B, SOD $1{ }^{693 A}$ or nontransgenic (Non- $\mathrm{Tg}$ ) motor neuron cultures were maintained in the presence of GDNF (1 $\mathrm{ng} / \mathrm{ml}$ ) and exposed to increasing concentrations of sFasL in the presence of vehicle or $\mathrm{BBH}$ $(500 \mathrm{~nm})$. SFasL was added in the presence of enhancer antibody $(1 \mu \mathrm{g} / \mathrm{ml}) 16 \mathrm{~h}$ after motor neuron plating, and survival was determined $48 \mathrm{~h}$ later. Data are expressed as percentage of its respective GDNF condition (mean $\pm \mathrm{SD}$ ). ${ }^{*} p<0.05$, significantly different from GDNF.

the nontargeted antioxidants and particularly effective in preventing cell death induced by oxidative mitochondrial damage in vitro and in vivo (Kelso et al., 2001; Jauslin et al., 2003; Dhanasekaran et al., 2004, 2005; Adlam et al., 2005). Moreover, mitoQ has been shown to cross the blood-brain barrier (Smith et al., 2003) and thus could be particularly useful to prevent mitochondrial oxidative damage and neuronal death induced by NGF/ p75 ${ }^{\text {NTR }}$-signaling in vivo.

It was previously shown that motor neurons overexpressing ALS-linked SOD1 mutations (G37R, G85R, or G93A) display increased susceptibility to activation of Fas apoptotic pathway, but not to trophic factor deprivation or excitotoxic death (Raoul et al., 2002). We show here that transgenic SOD1 ${ }^{\mathrm{G} 93 \mathrm{~A}}$ motor neurons also show increased susceptibility to $\mathrm{p} 75^{\mathrm{NTR}}$-mediated apoptosis. In contrast to nontransgenic motor neurons, SOD $1^{\text {G93A }}$ motor neurons are sensitive to NGF-mediated apoptosis in the absence of exogenous nitric oxide. Although an external source of nitric oxide is not required, NGF-induced apoptosis in SOD1 ${ }^{\mathrm{G} 93 \mathrm{~A}}$ transgenic motor neurons requires endogenous production of nitric oxide by nNOS, because apoptosis is prevented by nNOS inhibitors. Our results suggest the execution of a similar apoptotic pathway in nontransgenic and SOD $1^{\text {G93A }}$ motor neurons. The increased susceptibility of SOD1 ${ }^{\text {G93A }}$ motor neurons to NGF-induced apoptosis was not mediated by increased expression of $\mathrm{p} 75^{\mathrm{NTR}}$ or nNOS mRNA. However, increased nitric oxide production may still result from activation of endogenous NOS enzymatic activity. Nevertheless, for other apoptotic stimuli, including Fas (Raoul et al., 2002) and trophic factor deprivation (Estévez et al., 1998), nNOS regulation in motor neurons occurs at the transcriptional level. In nontransgenic motor neurons, basal nitric oxide production was counteracted by endogenous antioxidant defenses, and NGF-mediated apoptosis only proceeds in the presence of an exogenous source of nitric oxide, which overwhelmed antioxidant defenses. The expression of mutant SOD1 leads to decreased antioxidant defenses, thereby potentiating the detrimental stress of endogenous nitric oxide production. Together, our results suggest a critical modulation of the $\mathrm{p} 75^{\mathrm{NTR}}$-apoptotic pathway in motor neurons that is specifically regulated by the interaction with neighboring cells. NGF-mediated apoptosis will be executed only in the presence of surrounding cells producing nitric oxide or other diffusible factors capable to induce nitric oxide production or decrease antioxidant defenses in motor neurons.

$\mathrm{GSH}$, the most abundant nonprotein thiol present in mammalian cells, is particularly important in limiting the deleterious actions of nitric oxide in the nervous system (Dringen et al., 2000). GSH is synthesized by the consecutive action of the enzymes GCL and glutathione synthetase. GCL catalyzes the ratelimiting step in GSH biosynthesis and both subunits of the enzyme, GCLC and GCLM, are transcriptionally regulated by Nrf2, a redox-sensitive transcription factor and member of the Cap'n'Collar/basic-leucine zipper family (Nguyen et al., 2003). Compared with nontransgenic motor neurons, SOD $1{ }^{\mathrm{G} 93 \mathrm{~A}}$ motor neurons showed reduced Nrf2 mRNA expression, which correlated with a decreased transcription of GCLC and GCLM. A similar reduction in Nrf2 expression was previously observed in a motor neuron-like NSC34 cell line transfected with a mutant SOD1 expression vector and in motor neurons from SOD1associated familial ALS cases (Kirby et al., 2005). This reduction in Nrf2 expression could explain the increased susceptibility of SOD $1^{\text {G93A }}$ motor neurons not only to NGF but also to Fasmediated apoptosis, which also involves ROS and RNS production (Raoul et al., 2002). tBHQ has been established to strongly activate gene expression mediated by Nrf2 and to subsequently increase GSH content by induction of GCL. tBHQ causes increased GCL expression only when Nrf2 is present, but it does not in Nrf2 knock-out cells (Lee et al., 2003). Accordingly, pharmacological activation of Nrf2 by tBHQ treatment completely prevented NGF- and Fas-mediated motor neuron apoptosis in nontransgenic and SOD1 ${ }^{\text {G93A }}$ motor neurons. Thus, Nrf2 manipulation may be a target in the prevention of motor neuron death occurring in neuropathological conditions involving either p75 ${ }^{\text {NTR }}$ - or Fas-apoptotic signaling.

\section{References}

Adlam VJ, Harrison JC, Porteous CM, James AM, Smith RA, Murphy MP, Sammut IA (2005) Targeting an antioxidant to mitochondria decreases cardiac ischemia-reperfusion injury. FASEB J 19:1088-1095.

Arenz C, Thutewohl M, Block O, Waldmann H, Altenbach HJ, Giannis A (2001) Manumycin A and its analogues are irreversible inhibitors of neutral sphingomyelinase. Chembiochem 2:141-143.

Barker PA (2004) p75NTR is positively promiscuous: novel partners and new insights. Neuron 42:529-533.

Barrett GL (2000) The p75 neurotrophin receptor and neuronal apoptosis. Prog Neurobiol 61:205-229. 
Beckman JS, Koppenol WH (1996) Nitric oxide, superoxide, and peroxynitrite: the good, the bad, and ugly. Am J Physiol 271:C1424-C1437.

Beckman JS, Estévez AG, Crow JP, Barbeito L (2001) Superoxide dismutase and the death of motoneurons in ALS. Trends Neurosci 11:S15-S20.

Bhakar AL, Howell JL, Paul CE, Salehi AH, Becker EB, Said F, Bonni A, Barker PA (2003) Apoptosis induced by p75NTR overexpression requires Jun kinase-dependent phosphorylation of Bad. J Neurosci 23:11373-11381.

Birbes H, Bawab SE, Obeid LM, Hannun YA (2002) Mitochondria and ceramide: intertwined roles in regulation of apoptosis. Adv Enzyme Regul 42:113-129.

Brann AB, Tcherpakov M, Williams IM, Futerman AH, Fainzilber M (2002) Nerve growth factor-induced p75-mediated death of cultured hippocampal neurons is age-dependent and transduced through ceramide generated by neutral sphingomyelinase. J Biol Chem 277:9812-9818.

Casaccia-Bonnefil P, Carter BD, Dobrowsky RT, Chao MV (1996) Death of oligodendrocytes mediated by the interaction of nerve growth factor with its receptor p75. Nature 383:716-719.

Chao MV (2003) Neurotrophins and their receptors: a convergence point form many signalling pathways. Nat Rev Neurosci 4:299-309.

Copray JC, Jaarsma D, Kust BM, Bruggeman RW, Mantingh I, Brouwer N, Boddeke HW (2003) Expression of the low affinity neurotrophin receptor p75 in spinal motoneurons in a transgenic mouse model for amyotrophic lateral sclerosis. Neuroscience 116:685-694.

Cutler RG, Pedersen WA, Camandola S, Rothstein JD, Mattson MP (2002) Evidence that accumulation of ceramides and cholesterol esters mediates oxidative stress-induced death of motor neurons in amyotrophic lateral sclerosis Ann Neurol 52:448-457.

Dhanasekaran A, Kotamraju S, Kalivendi SV, Matsunaga T, Shang T, Keszler A, Joseph J, Kalyanaraman B (2004) Supplementation of endothelial cells with mitochondria-targeted antioxidants inhibit peroxide-induced mitochondrial iron uptake, oxidative damage, and apoptosis. J Biol Chem 279:37575-37587.

Dhanasekaran A, Kotamraju S, Karunakaran C, Kalivendi SV, Thomas S, Joseph J, Kalyanaraman B (2005) Mitochondria superoxide dismutase mimetic inhibits peroxide-induced oxidative damage and apoptosis: role of mitochondrial superoxide. Free Radic Biol Med 39:567-583.

Dobrowsky RT, Carter BD (1998) Coupling of the p75 neurotrophin receptor to sphingolipid signaling. Ann NY Acad Sci 845:32-45.

Dobrowsky RT, Werner MH, Castellino AM, Chao MV, Hannun YA (1994) Activation of the sphingomyelin cycle through the low-affinity neurotrophin receptor. Science 265:1596-1599.

Dringen R, Gutterer JM, Hirrlinger J (2000) Glutathione metabolism in brain. Metabolic interaction between astrocytes and neurons in the defense against reactive oxygen species. Eur J Biochem 267:4912-4916.

Estévez AG, Spear N, Manuel SM, Radi R, Henderson CE, Barbeito L, Beckman JS (1998) Nitric oxide and superoxide contribute to motor neuron apoptosis induced by trophic factor deprivation. J Neurosci 18:923-931.

Ferri CC, Moore FA, Bisby MA (1998) Effects of facial nerve injury on mouse motoneurons lacking the p75 low-affinity neurotrophin receptor. J Neurobiol 34:1-9.

Florez-McClure ML, Linseman DA, Chu CT, Barker PA, Bouchard RJ, Le SS, Laessig TA, Heidenreich KA (2004) The p75 neurotrophin receptor can induce autophagy and death of cerebellar Purkinje neurons. J Neurosci 24:4498-4509.

Garcia-Ruiz C, Colell A, Mari M, Morales A, Fernandez-Checa JC (1997) Direct effect of ceramide on the mitochondrial electron transport chain leads to generation of reactive oxygen species. Role of mitochondrial glutathione. J Biol Chem 272:11369-11377.

Gentry JJ, Barker PA, Carter BD (2004) The p75 neurotrophin receptor: multiple interactors and numerous functions. Prog Brain Res 146:25-39.

Gudz TI, Tserng KY, Hoppel CL (1997) Direct inhibition of mitochondrial respiratory chain complex III by cell-permeable ceramide. J Biol Chem 272:24154-24158.

Henderson CE, Camu W, Mettling C, Gouin A, Poulsen K, Karihaloo M, Rullamas J, Evans T, McMahon SB, Armanini MP, Berkemeier L, Phillips HS, Rosenthal A (1993) Neurotrophins promote motor neuron survival and are present in embryonic limb bud. Nature 363:266-270.

Henderson CE, Bloch-Gallego E, Camu W (1995) Purification and culture of embryonic motor neurons. In: Neural cell culture: a practical approach (Cohen J, Wilkin G, eds), pp 69-81. Oxford: IRL.

Howland DS, Liu J, She Y, Goad B, Maragakis NJ, Kim B, Erickson J, Kulik J, DeVito L, Psaltis G, DeGennaro LJ, Cleveland DW, Rothstein JD (2002)
Focal loss of the glutamate transporter EAAT2 in a transgenic rat model of SOD1 mutant-mediated amyotrophic lateral sclerosis (ALS). Proc Natl Acad Sci USA 99:1604-1609.

Jauslin ML, Meier T, Smith RA, Murphy MP (2003) Mitochondria-targeted antioxidants protect Friedreich Ataxia fibroblasts from endogenous oxidative stress more effectively than untargeted antioxidants. FASEB J 17:1972-1974.

Johnson DA, Andrews GK, Xu W, Johnson JA (2002) Activation of the antioxidant response element in primary cortical neuronal cultures derived from transgenic reporter mice. J Neurochem 81:1233-1241.

Kelso GF, Porteous CM, Coulter CV, Hughes G, Porteous WK, Ledgerwood EC, Smith RA, Murphy MP (2001) Selective targeting of a redox-active ubiquinone to mitochondria within cells: antioxidant and antiapoptotic properties. J Biol Chem 276:4588-4596.

Kirby J, Halligan E, Baptista MJ, Allen S, Heath PR, Holden H, Barber SC, Loynes CA, Wood-Allum CA, Lunec J, Shaw PJ (2005) Mutant SOD1 alters the motor neuronal transcriptome: implications for familial ALS. Brain 128:1686-1706.

Koliatsos VE, Crawford TO, Price DL (1991) Axotomy induces nerve growth factor receptor immunoreactivity in spinal motor neurons. Brain Res 549:297-304.

Kuner P, Hertel C (1998) NGF induces apoptosis in a human neuroblastoma cell line expressing the neurotrophin receptor p75NTR. J Neurosci Res 54:465-474.

Kust BM, Brouwer N, Mantingh IJ, Boddeke HW, Copray JC (2003) Reduced p75NTR expression delays disease onset only in female mice of a transgenic model of familial amyotrophic lateral sclerosis. Amyotroph Lateral Scler Other Motor Neuron Disord 4:100-105.

Lee JM, Calkins MJ, Chan K, Kan YW, Johnson JA (2003) Identification of the NF-E2-related factor-2-dependent genes conferring protection against oxidative stress in primary cortical astrocytes using oligonucleotide microarray analysis. J Biol Chem 278:12029-12038.

Lowry KS, Murray SS, Coulson EJ, Epa R, Bartlett PF, Barrett G, Cheema SS (2001a) Systemic administration of antisense p75(NTR) oligodeoxynucleotides rescues axotomised spinal motor neurons. J Neurosci Res 64:11-17.

Lowry KS, Murray SS, McLean CA, Talman P, Mathers S, Lopes EC, Cheema SS (2001b) A potential role for the p75 low-affinity neurotrophin receptor in spinal motor neuron degeneration in murine and human amyotrophic lateral sclerosis. Amyotroph Lateral Scler Other Motor Neuron Disord 2:127-134.

Luberto C, Hassler DF, Signorelli P, Okamoto Y, Sawai H, Boros E, HazenMartin DJ, Obeid LM, Hannun YA, Smith GK (2002) Inhibition of tumor necrosis factor-induced cell death in MCF7 by a novel inhibitor of neutral sphingomyelinase. J Biol Chem 277:41128-41139.

Mansat-de Mas V, Bezombes C, Quillet-Mary A, Bettaieb A, D'orgeix AD, Laurent G, Jaffrezou JP (1999) Implication of radical oxygen species in ceramide generation, c-Jun $\mathrm{N}$-terminal kinase activation and apoptosis induced by daunorubicin. Mol Pharmacol 56:867-874.

Marchesini N, Hannun YA (2004) Acid and neutral sphingomyelinases: roles and mechanisms of regulation. Biochem Cell Biol 82:27-44.

Nguyen T, Sherratt PJ, Pickett CB (2003) Regulatory mechanisms controlling gene expression mediated by the antioxidant response element. Annu Rev Pharmacol Toxicol 43:233-260.

Nykjaer A, Willnow TE, Petersen CM (2005) p75NTR—live or let die. Curr Opin Neurobiol 15:49-57.

Pehar M, Cassina P, Vargas MR, Castellanos R, Viera L, Beckman JS, Estevez AG, Barbeito L (2004) Astrocytic production of nerve growth factor in motor neuron apoptosis: implications for amyotrophic lateral sclerosis. J Neurochem 89:464-473.

Pehar M, Vargas MR, Robinson KM, Cassina P, England P, Beckman JS, Alzari PM, Barbeito L (2006) Peroxynitrite transforms nerve growth factor into an apoptotic factor for motor neurons. Free Radic Biol Med 41:1632-1644.

Quillet-Mary A, Jaffrezou JP, Mansat V, Bordier C, Naval J, Laurent G (1997) Implication of mitochondrial hydrogen peroxide generation in ceramideinduced apoptosis. J Biol Chem 272:21388-21395.

Radi R, Cassina A, Hodara R, Quijano C, Castro L (2002) Peroxynitrite reactions and formation in mitochondria. Free Radic Biol Med 33:1451-1464.

Raoul C, Estevez AG, Nishimune H, Cleveland DW, deLapeyrière O, Henderson CE, Haase G, Pettmann B (2002) Motoneuron death triggered by a 
specific pathway downstream of Fas: potentiation by ALS-linked SOD1 mutations. Neuron 35:1067-1083.

Rende M, Giambanco I, Buratta M, Tonali P (1995) Axotomy induces a different modulation of both low-affinity nerve growth factor receptor and choline acetyltransferase between adult rat spinal and brainstem motoneurons. J Comp Neurol 363:249-263.

Robinson KM, Janes MS, Pehar M, Monette JS, Ross MF, Hagen TM, Murphy MP, Beckman JS (2006) Selective fluorescent imaging in the cytosolic and mitochondrial compartments using ethidium probes. Proc Natl Acad Sci USA 103:15038-15043.

Seeburger JL, Tarras S, Natter H, Springer JE (1993) Spinal cord motoneurons express p75NGFR and p145trkB mRNA in amyotrophic lateral sclerosis. Brain Res 621:111-115.

Sendtner M, Pei G, Beck M, Schweizer U, Wiese S (2000) Developmental motoneuron cell death and neurotrophic factors. Cell Tissue Res 301:71-84.

Smith RA, Porteous CM, Gane AM, Murphy MP (2003) Delivery of bioactive molecules to mitochondria in vivo. Proc Natl Acad Sci USA 100:5407-5412.

Snider WD (1994) Functions of the neurotrophins during nervous system development: what the knockouts are teaching us. Cell 77:627-638.

Turner BJ, Cheah IK, Macfarlane KJ, Lopes EC, Petratos S, Langford SJ,
Cheema SS (2003a) Antisense peptide nucleic acid-mediated knockdown of the p75 neurotrophin receptor delays motor neuron disease in mutant SOD1 transgenic mice. J Neurochem 87:752-763.

Turner BJ, Rembach A, Spark R, Lopes EC, Cheema SS (2003b) Opposing effects of low and high-dose clozapine on survival of transgenic amyotrophic lateral sclerosis mice. J Neurosci Res 74:605-613.

Vargas MR, Pehar M, Cassina P, Beckman JS, Barbeito L (2006) Increased glutathione biosynthesis by Nrf2 activation in astrocytes prevents p75NTR-dependent motor neuron apoptosis. J Neurochem 97:687-696.

Wang X, Bauer JH, Li Y, Shao Z, Zetoune FS, Cattaneo E, Vincenz C (2001) Characterization of a p75(NTR) apoptotic signaling pathway using a novel cellular model. J Biol Chem 276:33812-33820.

Wiese S, Metzger F, Holtmann B, Sendtner M (1999) The role of p75NTR in modulating neurotrophin survival effects in developing motoneurons. Eur J Neurosci 11:1668-1676.

Yan Q, Elliott JL, Matheson C, Sun J, Zhang L, Mu X, Rex KL, Snider WD (1993) Influences of neurotrophins on mammalian motoneurons in vivo. J Neurobiol 24:1555-1577.

Yoon SO, Casaccia-Bonnefil P, Carter B, Chao MV (1998) Competitive signaling between TrkA and p75 nerve growth factor receptors determines cell survival. J Neurosci 18:3273-3281. 